\title{
Article
}

\section{Establishing Social Work Practices in England: The Early Evidence}

Stanley, Nicky, Austerberry, Helen, Bilson, Andy, Farrelly, Nicola, Hargreaves, Katrina, Hussein, Shereen, Ingold, Anne, Manthorpe, Jill, Ridley, Julie and Strange, Vicki

Available at http://clok.uclan.ac.uk/5431/

Stanley, Nicky ORCID: 0000-0002-7644-1625, Austerberry, Helen, Bilson, Andy, Farrelly, Nicola, Hargreaves, Katrina, Hussein, Shereen, Ingold, Anne, Manthorpe, Jill, Ridley, Julie ORCID: 0000-0002-0879-308X et al (2012) Establishing Social Work Practices in England: The Early Evidence. The British Journal of Social Work . pp. 1-17. ISSN 0045-3102

It is advisable to refer to the publisher's version if you intend to cite from the work. 10/1093/bjsw/bcs101

For more information about UCLan's research in this area go to http://www.uclan.ac.uk/researchgroups/ and search for <name of research Group>.

For information about Research generally at UCLan please go to http://www.uclan.ac.uk/research/

All outputs in CLoK are protected by Intellectual Property Rights law, including Copyright law. Copyright, IPR and Moral Rights for the works on this site are retained by the individual authors and/or other copyright owners. Terms and conditions for use of this material are defined in the policies page.

\section{CLoK}

Central Lancashire online Knowledge www.clok.uclan.ac.uk

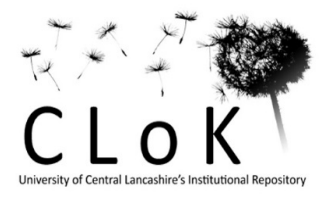


Establishing Social Work Practices in England: The

Early Evidence

Nicky Stanley, Helen Austerberry, Andy Bilson, Nicola

Farrelly, Katrina Hargreaves, Shereen Hussein, Anne

Ingold, Jill Manthorpe and Julie Ridley 


\begin{abstract}
Social Work Practices (SWPs) were established in England in 2009 to deliver social work services to looked after children and care leavers. The introduction of independent social work-led organisations generated controversy focused on issues such as the privatisation of children's services and social workers' conditions of employment. This paper reports early findings from the evaluation of four of these pilots drawing on interviews with children and young people, staff and local authority and national stakeholders.
\end{abstract}

The SWPs assumed a variety of organisational forms. The procurement process was demanding with protracted negotiations over matters such as budgetary control and providing a round-the-clock service. Start-up was facilitated by an established relationship between the SWP provider and the local authority. Once operational, SWPs continued to rely on local authorities for various functions; in most cases, local authorities retained control of placement budgets. Levels of consultation and choice offered to children and young people regarding the move to an SWP varied considerably. Children's understanding about SWPs was generally low except in the pilot where most children retained their original social worker.

These early findings show some dilution of the original SWP model while the pilots' diversity allows the benefits of particular models to emerge. 


\section{Background}

Social Work Practices (SWPs) were introduced in England by the New Labour government against a background of initiatives that included Every Child Matters (Department for Education and Skills 2003) and a drive to improve outcomes for looked after children. Piloting of SWPs was first proposed in the Care Matters Green Paper (Secretary of State for Education and Skills, 2006) where they were conceptualised as autonomous organisations, similar to General Practices (GPs) where self-employed family physicians run profit-making services which work under contract to the NHS. It was envisaged that SWPs would be contracted by local authorities to provide specific services to looked after children. They could take a variety of organisational forms such as social enterprises, voluntary or community organisations or private businesses. The aim was for social workers to be freed from the restrictions imposed by local authority procedures and the demands of crisis work and high caseloads in order to focus their efforts and energies on looked after children. The report of the working party (Le Grand 2007) subsequently provided the platform for the implementation of SWPs arguing that smaller social worker-led organisations independent of local authorities could improve the morale and retention of social workers and would bring decision-making closer to front-line practice. These changes were expected to deliver a level of consistency and stability of care for looked after children and care leavers that had proved difficult to achieve (Department of Children, Schools and Families, 2007). However, as the report noted, the question of whether social workers in SWPs would have more 'hands-on time for building relationships with looked after children, remains open' (Le Grand, 2007 p24). The Children and Young Persons Act 2008 provided the legislative framework for the piloting of SWPs and established that evaluation would be the basis for any decision 
to extend SWPs to all local authorities. The Act permitted local authorities to transfer responsibilities for the care of looked after children to social work providers who were not local authorities, specifying that the functions transferred would be undertaken by or supervised by registered social workers, and established a five year period for SWPs to be piloted.

SWPs have proved ideologically attractive to the current Coalition Government for their capacity to embody alternative models such as social enterprises for delivering welfare services, so dovetailing with Government's Big Society agenda. Delivering services such as social work outside the local authority also contributes to the aim of reducing the size of the public sector (HM Government, 2010). In 2011, the Department for Education announced two further tranches of SWPs for looked after children while the Department for Health enabled six SWP pilots for adults.

Piloting social work practices (SWPs) for looked after children in England has been controversial. Although various services formerly provided in-house by local authority children's social services have been outsourced for many years, notably residential child care and independent fostering agencies (whose function is restricted to placement finding and support and excludes direct work with children) (Sellick 2011a), introducing SWPs entailed moving some aspects of the statutory roles and tasks of children's social workers outside the local authority into independent organisations. The only organisation other than local authorities to own and exercise similar statutory powers is the National Society for Prevention of Cruelty to Children (NSPCC), one of 
the largest and oldest voluntary organisations in the UK. The NSPCC has Authorised Persons Status which confers the ability to make applications to the family court to safeguard the welfare of children at risk of significant harm and to undertake the assessment of such children. However, these powers appear to have fallen into disuse (NSPCC, personal communication). The introduction of SWPs was depicted as an attempt to bring quasi-markets into welfare and was described by critics as the privatisation of children's welfare services and the commodification of children (Cardy, 2010; Garrett, 2008).

The out-sourcing of children's services and the privatisation of the sector has been a feature of United States (US) welfare services since 1997 when the States of Kansas and Florida spearheaded the development by privatising their entire foster care services (Snell, 2000). Other States have followed by contracting out intensive family intervention services and adoption services on a large scale. McCullough and Schmitt's (2000) US survey found that 59 percent of States had one or more privatisation initiatives underway; the majority involved contracting with not-for-profit organisations to deliver and manage services. However, research with child welfare administrators in 2006 indicated that the majority of states retained responsibility for case management of child welfare services in the public sector with ten percent shifting case management to the private sector on a large scale and a further 20 percent reporting smaller scale initiatives (Collins-Camargo et al, 2008). Snell's (2000) account of early privatisation initiatives in the US found that they delivered on outcome measures, reducing length of stay in the care system and the average number of placements and increasing staff's 
face-to-face contacts with children. However, Snell also reported that privatisation could result in more children entering the care of the state since, freed from the work involved in caring for looked after children, state social workers had more time for investigating child abuse. Zullo (2006) noted that the use of quasi markets in child welfare in the US created problems when private providers focused on incentives built into contracts rather than on children's needs. In the UK context, Sellick (2011b) identified difficulties of cost containment in relation to the privatisation of fostering services and noted polarised perceptions of private fostering agencies that were seen as either predators or pioneers. Similarly, the relationship between these agencies and local authorities was variously depicted as either partnership or procurement.

Garrett's (2008) early critique of SWPs rested on two key points: first he argued that the characterisation of the looked after system as a 'failing system' is primarily ideological and does not take account of the complexity of experience that the care system encompasses. In this, he drew on the arguments of researchers such as Stein (2006) and Forrester et al (2009) who have emphasised the heterogeneity of children's experiences in the looked after system and who maintain that outcomes for looked after children reflect the needs that bring them into care. Second, Garrett claimed that SWPS were introduced without meaningful consultation of looked after children or their parents Other critics have suggested that SWPs will be required to meet the same bureaucratic demands as local authority children's services, particularly in relation to the much criticised electronic records system, the Integrated Children's System (Cardy, 2010). Queries have also been raised as to whether practitioners have the business skills and 
knowledge to develop the necessary business plans to run an independent SWP and whether sufficient thought has been given to calculating both costs and risks (Cardy, 2010). The professional press has been more even-handed in its coverage, reporting both the achievements of SWPs and articulating resistance (Brody, 2010; Lombard, 2010; Mahadevan, 2010).

Some of these anticipated improvements and challenges are explored in the early work of the national evaluation of SWPs reported here. This paper reports findings from the first stage of the process evaluation focusing on the implementation of the pilots, the various forms they have assumed and the nature of their relationships with the commissioning local authorities. It aims to set out emerging findings from the evaluation of a policy development in children's services likely to prove influential for the policy, research and practice communities. At the time of writing (November 2011), the evaluation is still in progress so little can be said here about the nature of professional practice within the SWPs or about outcomes for children and how these compare to local authority practice and outcomes. These findings will be reported in future papers. In common with other evaluations commissioned by the UK Government in recent years (Berridge, 2011), this evaluation has found that political enthusiasm for the intervention under scrutiny has run ahead of its timetable. Nevertheless, the early findings from this study offer some pertinent lessons for the next wave of SWPs currently being developed in both children's and adults' services and for broader changes in social work services.

\section{Methodology}


The evaluation was designed as a matched control study (Breslow, 1996) to include five pilot SWP sites and six comparison sites (one pilot site failed to start up). A mixed methods approach (Creswell, 2009) is being used to gather evidence about the processes and the impact of SWPs, through the use of interviews, large-scale surveys, analysis of documentation, and through the collation of existing local and national data. The evaluation which started in December 2008 and reports in Spring 2012 will capture and reflect a range of perspectives including the views of children and young people, parents, carers, SWP staff, local authority staff and other professionals.

This paper presents findings from interviews with a range of professional stakeholders involved in SWPs in the planning period preceding their implementation and in the first year of operation, and from interviews with children and young people in the first year after start up. An account of the early process of setting up the pilots was captured through 12 interviews with key stakeholders who included five SWP project managers appointed by local authorities to support the commissioning and implementation of the SWPs; two children's service managers; three Government appointed consultants involved in supporting both local authority commissioners and SWP providers, a member of the SWP Expert Group convened by the then Department for Children Schools and Families and a trades union representative. These interviews were carried out in Summer 2009, after the SWP providers had been selected but several months before pilots started up. A second set of 12 face-to-face interviews was completed with SWP staff a year later when four SWPs were operational; a manager, a qualified social worker and a non-social work qualified practitioner such as a Personal Adviser were interviewed in each pilot. 
Children's early experiences of the SWPs were explored through interviews with 80 children and young people from the four SWPs operational at that time. The sample was constructed to reflect the total population of children and young people transferred to the four SWPs. Those children and young people selected for interview were invited to participate in the study by SWP staff on behalf of the researchers. Around half those initially selected were unavailable or refused an interview and were substituted with another child/young person with a similar profile. This may have meant that the researchersdid not have access to those children or young people most likely to be unhappy with the service they were receiving or those in most difficult circumstances. However, researchers' dependence on practitioners as gatekeepers to children is a common challenge in research with children who use services (Hutchfield and Coren, 2011) and those children and young people participating in this study were found to express a wide range of views and experiences.

All participants were provided with appropriate information about the research and informed consent procedures were adopted. Interviews were recorded and transcribed, and a commitment to anonymity was given. Transcripts were coded using NVivo software in order to facilitate thematic analysis using themes identified both from the literature and those emerging from the data (Coffey and Atkinson, 1996). Ethical approval for the study was provided by the (Institution) Ethics Committee. 
Other information made available to the research team and utilised here includes data provided by the SWPS describing both their cohorts of children and their staffing. Researchers also read and analysed the contracts used to commission the SWPs.

\section{The Social Work Practice Pilots}

Out of the original six SWP pilots one failed to start as, although a provider was identified, the local authority was distracted from the task of introducing an SWP by the need to respond to an Ofsted inspection. A second SWP started up six months after the other four when, following considerable debate and negotiation, it was agreed that, although this pilot would be constituted as a separate unit, it would remain within the local authority and legal responsibilities for the children would not be transferred. The delays in start-up for this SWP meant that it was not possible to collect some of the early process data, such as interviews with children and young people, available from the other SWP sites.

The remaining four SWP pilots differ in their organisational forms, in the cohorts of children and young people they work with and in their size. Two (SWPs B and C) are operated by large and well-established voluntary sector organisations, one of which (SWP B) already held the contract to provide a care leaving service across the local authority prior to being designated as a SWP. This pilot is unique in having no cap or limit on the very substantial cohort of young people leaving the care of the local authority (care leavers) with whom it has agreed to work. One pilot (SWP D) is constituted as a not-for-profit social enterprise and this SWP was established through a 
process whereby a team of social workers from within the local authority moved with the children and young people on its caseload (together with additional cases) outside the local authority to become an independent organisation. The fourth pilot (SWP A) is a private company, formerly a social care training company, whose owners used the opportunity to bid for an SWP pilot to move into service delivery. Table 1 shows the organisational model and the cohort with which the SWP works in respect of these four pilots.

Table 1 Social Work Practice Pilots - Models and Cohorts at June 2010

\begin{tabular}{|l|l|l|}
\hline Pilot & SWP model & Cohort of Children \& Young People \\
\hline A & $\begin{array}{l}\text { Private, for profit } \\
\text { Company }\end{array}$ & $\begin{array}{l}\text { c.80 children with high levels of need } \\
\text { age group: 10+ }\end{array}$ \\
\hline B & $\begin{array}{l}\text { Established voluntary } \\
\text { organisation }\end{array}$ & $\begin{array}{l}\text { c. } 600 \text { young people } \\
\text { age group: 16-24 }\end{array}$ \\
\hline C & $\begin{array}{l}\text { Established voluntary } \\
\text { organisation }\end{array}$ & $\begin{array}{l}\text { c. 120 young people representative } \\
\text { of overall looked after children populatio }\end{array}$ \\
\hline D & $\begin{array}{l}\text { Social enterprise }- \\
\text { professional partnership } \\
\text { owned and run by } \\
\text { practitioners (not for } \\
\text { profit) }\end{array}$ & c. 150 children \& young people \\
age group: primarily 13+
\end{tabular}

\section{Commissioning SWPs}

The Green Paper (Secretary of State for Education and Skills 2006) and subsequently the working party report (Le Grand, 2007) identified three key forms of governance for SWPs: the professional partnership owned and run by practitioners which might be for-profit or notfor-profit, the voluntary sector model, and the private sector SWP. The tendering process in 
the four local authorities was shaped to reflect local authorities' preferences for specific models. The local authority that wanted to pilot a third sector model with an existing provider advertised the tender to voluntary sector organisations it already worked with and specified that bidders should be able to evidence "proven expertise and quality of delivery". Another local authority sought bids from groups of social workers currently employed in its children's services. Only one local authority adopted a completely open procurement process.

The procurement or tendering process was identified as one of the most challenging aspects of setting up the SWPs by the stakeholders interviewed. Local authority procurement procedures were described as restrictive and weighted in favour of the commissioner rather than the provider. Despite Government appointed consultants being available to provide advice and guidance to both the commissioning local authorities and those preparing tenders, some groups of social workers who were coming together as a group or partnership for the first time specifically to bid for a SWP, were reported to have found preparing a bid too onerous on top of existing responsibilities and so withdrew from bidding. Existing organisations with the infrastructure to support engagement in tendering processes fared better with these processes.

A thorny issue highlighted by the interviews was the extent of decision-making and budgetary responsibility to be delegated to the SWP by the agreed contracts. A range of arrangements allowing varying degrees of control over budgets was commissioned. Local authorities were reported to be reluctant to delegate financial control where SWPs had no track record of managing large budgets nor the economy of scale to absorb large budgetary fluctuations associated with high cost placements. In the event, only one SWP, that which 
worked solely with care leavers, had full control of the placement budget. This arrangement left most SWPs dependant on the local authority regarding major spending decisions on placements.

One aspect of SWPs specified by the working party report (Le Grand 2007) was that, in the interests of being accessible to children and carers, pilots should provide a round-the-clock service. Agreeing remuneration to providers in this respect proved a difficult negotiating point in some sites. According to local authority project managers, several organisations subsequently withdrew from bidding because they were not convinced that the funding on offer was sufficient to deliver this service.

A further challenge concerned payment by results (PBR), a feature of SWPs designed to stimulate performance (Le Grand, 2007). Some potential providers were unwilling to commit to a system of PBR before they had some experience of delivering the service. In the event, PBR was built into the contract in two of the four sites where PBR was set up as a reward system for staff for any savings made on the placement budgets. In these cases, the early interpretation of PBR focused on cost reduction rather than improving outcomes for looked after children.

While some local authorities assessed more than one bid from potential SWP providers, others had only one suitable proposal to consider. Some local authorities involved young people in the selection stage; typically, this involved bidders delivering a presentation to a panel of young people. Some bids were considered too expensive and costs were 
renegotiated with potential providers. Elsewhere, local authority managers were explicit that cost considerations were secondary to ensuring quality of service.

\section{Transferring Children and Information}

Offering increased continuity and consistency to looked after children and young people was an explicit aim of the Green Paper but paradoxically, transfer to an SWP entailed a change of social worker or Personal Adviser for some children and young people. In SWP D, the majority of the cohort was already known to SWP staff since children and young people transferred alongside their local authority social workers who moved into the SWP. In SWP B, the service had already been working for the local authority's care leavers prior to taking on SWP status. In this site, young people continued to transfer into the SWP after the exams following their 16th birthday, and there was an established system of planned meetings and information transfer to facilitate this process. Transition of the cohort into SWP pilots appeared to have been least problematic where continuity was maintained for both children and practitioners:

“...it was quite plain sailing, it worked really well, there were no issues, we just all moved across quite nicely, they knew there was consistency, so there was no change of workers but again that was planned and introductions took place before we all moved, so it worked really well" (SWP D)

In contrast, where the cohort was not known to them, SWP staff faced a number of challenges. These included difficulties gaining the trust and respect of some of the parents and carers who regretted losing long term relationships with their previous local 
authority workers. Where the children were not known to them, SWP staff found it useful to have face-to-face meetings with the previous social worker and the opportunity to refer back to the previous social worker was also welcomed.

Transfer of case files appeared to be a relatively smooth process in SWPs B and D. In the case of new children entering these SWPs, it was established that new cases were not accepted unless case files were up-to-date and both SWPs had clear protocols regarding transfer of information:

"If it's got gaps we don't accept transfer, they know what our expectation is because we send the transfer checklist, so they know all the paper work we want, and if there's significant gaps, we'll make them go back and come again" $(S W P D)$

In contrast, for SWPS A and C, where the cohort was not previously known to staff, the transfer of case files was experienced as problematic. In both these sites, SWP staff reported that attempts by local authority staff to update files resulted in significant delays in sending them over. Some SWP staff began work with only a transfer summary for a case and without knowing children's full background. Where case notes were incomplete at handover, SWP staff could be anxious about contact with parents who represented an unknown quantity, and some staff preferred to minimise such contact. In some cases, essential information missing from case files was difficult and time consuming to obtain:

"Well I don't have a proper handover really on most of my cases and the information I need is not on the system, [the files] are somewhere in an office that 
we can't get into easily and then they're thrown in a filing cabinet in no systematic way...so I'm ringing everybody and asking everybody and not getting much joy really" (SWP C)

In retrospect, staff felt that this SWP should have adopted the approach taken in other pilots where it was agreed that information would be transferred before cases were accepted by the SWP.

\section{Children and Young People's Understanding and Choices}

When interviewed in the year following pilot start-up, most children and young people had very limited understanding of what an SWP was and how it differed from local authority services. Many had been 'told something' but could not remember much about it. This young person's comments convey his somewhat weary sense of having a long series of professionals and agencies involved in his life:

"I don't really know a lot about [it]... to be honest I thought it was still the same thing, I don't know no difference, like, is this another borough like, or whatever, it's just another thing, in'it?" (16 year old, looked after boy)

However, children and young people in SWP D were more likely to understand that the SWP was 'a small team' and that the service would be 'quicker'. This enhanced level of recognition seemed to be associated with the involvement of children and young people in the development of the SWP as well as in the consultation groups that the pilot subsequently 
operated and the fact that the SWP's identity was embodied by its location in its own accessible and child-friendly premises:

"Well that they can make decisions quickly and they've got like a budget of the money and they can do, I think they can do trips, work experience they can do, they've changed their name, they've got a forum, which is a group which is made up of children in care. . . and then they've got another ... which is for people who are leaving care and they've got like this big building which I like." (13 year old, looked after boy)

SWP D was also the pilot where children and young people were most likely to have known their social worker or Personal Adviser prior to the transfer since this was the SWP where most of the staff and children and young people moved out of the local authority together. These children may therefore have been better prepared and informed about SWPs since their social workers would have had a high stake in the venture.

The extent to which children and young people felt that they had exercised choice with regard to the decision to move to the SWP also `varied considerably. In SWP B, young people had had no choice whether or not they would join the SWP since it was the only service available for care leavers; elsewhere, there was a mixture of those who felt they had had some degree of choice and those who felt they were "just told that's what's happening." (13 year old, looked after boy). Many of those who described choosing to be part of the SWP reported being told they were to be in the SWP and then asked what they felt about it. A number expressed indifference, often because they did not perceive it as any different from what they would have been offered through traditional social work or leaving care teams. Others who had little knowledge of SWPs were prepared to 
"give anything a try". Many could not remember whether or not they had been asked to be part of the SWP, or remembered being asked but did not mind one way or the other. Some SWP staff noted that children and carers had not been given clear and sufficiently early choices about whether they wanted to enter the SWP and may have only been informed at a point when there was insufficient time available for them to resist the change:

"Clearly somebody's made a decision not to inform the social worker or the child or family until not last minute but towards the end... if it's going to happen next week or the week after it's a fait accompli, it's happened." (SWP C)

Commonly, where children and young people had taken a conscious decision to transfer to the SWP, it was to ensure continuity of worker, either of social worker or Personal Adviser (PA), especially where they had an established relationship:

"I would lose my Social Worker when I'm 18 anyway. I chose to keep like my PA because I know, I'd know her, I know her better anyway so it wasn't such a difficult to change Social Workers...." (17 year old, looked after girl)

In a small number of cases, children and young people expressed anger about their lack of involvement in the decision to move to a SWP:

"I think, sometimes I think the Social Services doesn't really think about the kids, I think they just think about themselves because think about it, I knew S all my, nearly all my life yeah, and then they just go and change it, they didn't think about 
the kids when they changed it, they just changed it...I don't think they took two seconds to look at it, they just changed it, that's my personal point of view..." (14 yr old, looked after boy)

For this young person, the change in social worker was experienced as negative because he lost a valued relationship and felt that his views about this were discounted. These feelings were much less likely to be evinced by those children and young people who had anticipated a change of social workers because they knew they would move to a care leavers service or because they had been informed and consulted about the move to SWPs. Some children and young people appeared to be habituated to changes of social worker or did not perceive the service as new or different.

\section{Relationships with Local Authorities}

The self-governing SWP model was planned to avoid social work staff feeling demotivated, overwhelmed by bureaucracy and deprived of autonomy. The intention was to replace rule-based managerial accountability with knowledge-based professional accountability, where there would be freedom to make efficiency savings and to innovate (Le Grand, 2007).- However, staff in all four SWPs were keen to foster a close relationship with the local authority and valued a partnership where the local authority embraced rather than isolated the SWP and where communication was ongoing:

"You need regular meetings to make sure that everything's ticking over... and it's people listening to each other...views must be put straight-forwardly." $(S W P A)$ 
A good relationship with the local authority was deemed critical to the functioning of the SWP in order to facilitate an efficient hand-over of up-to-date cases; effective negotiations concerning placement decisions; and fair performance monitoring. Staff in pilots with established histories of working with the local authority considered that it took time for a SWP to establish credibility and for the local authority to trust the SWP enough to relinquish control:

"[Some] social work practices were having a difficult time dividing from the local authority and the local authority wanting to have a lot of control over what they did... Our managers work very hard to establish credibility with the local authority over the years, [achieved] partly because that's been so many years that they've worked with them." (SWP B)

The Le Grand (2007) report had envisaged that each SWP would hold a budget and use it for individual social workers to fund the placement, support and activities they believed each individual child on their caseload required. In practice, the degree to which local authorities devolved control over budgets and placements to SWPs varied with SWP B (which was responsible for care leavers only) alone taking full responsibility for the placement budget. Similarly, while SWP D controlled the budget forits care leavers, the local authority retained control of the placement budget for looked after children but gave the SWP some control over how funding earmarked for these children was spent. SWP A had no control over the placement budget which SWP staff considered to reflect a lack of trust on the local authority's part. All local authorities 
devolved operational budgets for support and activities for children and young people to the SWP or to the parent voluntary organisation operating the SWP.

There was further variation in the extent to which SWPs had autonomy: SWPs, to differing degrees, relied on local authorities for a range of services and support, including supervision (one SWP manager described receiving supervision from the local authority), training, information technology, rental of local authority premises and equipment, and legal services. While the pilots did not take on responsibilities for safeguarding work with children not in the looked after system, they responded to any safeguarding issues that arose in respect of those for whom they were providing services. In three SWPs, the local authority was providing the expertise required for court work and addressing safeguarding issues and SWPs were seen to benefit from local authority input in respect of complex high risk cases:

“...probably managers at a higher level [in the SWP's parent organisation] don't have the hands on child protection experience in this organisation that you might get in another organisation that is more dedicated to children's services...I think that's why it's really important for us to have good links with local authority managers." (SWP C)

We noted above that the concept of the SWP providing a round-the-clock service proved contentious at the commissioning stage and some SWPs reported that the requirement to participate in an out-of-hours service hampered recruitment of staff. Six 
months after start-up only one pilot, SWP D, was running a comprehensive out-of-hours service that staff judged to be well used. SWPs B and C both piloted partial in-house out-of-hours services but found uptake to be limited. SWP A had been keen to operate its own out-of-hours service but this was not included in the contract. Although these three SWPs had arrangements that allowed children and carers to contact staff on mobile telephones out-of-hours, they retained some dependency on local authorities' out-of-hours services.

\section{Discussion - Continuity, Change and Choice}

Unsurprisingly, implementation has resulted in dilution or adaptation of the original SWP model. Some of the more controversial aspects of SWPs identified in the literature and professional press, such as payment by results and the concept of a round-the-clock service for looked after children, have not materialised at this stage in all pilots. The SWPs have continued to rely on local authorities for a range of functions including management of placement budgets, out-of-hours services, training, supervision of a SWP manager, legal advice and expertise in safeguarding. When it works smoothly, this interdependency between the SWPs and the local authorities resembles a collaborative partnership rather than a standard purchaser-provider arrangement. US research provides some support for the value of collaborative relationships between public commissioners and private providers of foster care services. Flaherty et al's (2008) study of the lessons learnt in privatising children's welfare services in 12 US states highlighted the importance of a high level of trust and open communication between public sector commissioners and private sector providers. Zullo (2006) 
analysed the allocation of cases between the public services and five independent agencies over periods of up to 35 years and identified a collaborative model whereby the public services commissioners developed long-term partnerships with private providers that allowed for cases to be distributed between the public and private sectors in a way that drew on the particular expertise of those private agencies.

However, there is early evidence from some pilots of difficulties in achieving a smooth collaborative relationship. These difficulties relate to initial disagreements about the devolution of certain functions such as the out-of-hours service and control of budgets as well as to delays and barriers encountered in the process of establishing the SWPS. The ease experienced in setting up a pilot was also mediated by the SWP's relationship with the local authority. This was evident where staff groups were already constituted as an established local authority team working with the SWP cohort of children and young people, or where there was already an established relationship of trust and confidence between the SWP provider and the local authority.

In two pilots, the cohort of children and young people retained the same key worker they had prior to moving to the SWP, and transfer was generally unproblematic. In the other pilots, children's transfer to the SWP necessitated a change of social worker or Personal Adviser which required new relationships to be built. In some cases, this change was not welcomed by children and staff also identified initial resistance and suspicion from some parents or carers; accompanying delays in the transfer of case files created difficulties for practitioners. 
Concerns about whether meaningful consultation took place with children entering SWPs appeared to have been borne out by the fact some children and young people were clear that they were not given a choice about whether they wanted to join the SWP. Others seemed to have made the choice within constraints or in an uninformed way. This lack of opportunity to exercise choice was likely to have an impact on how relationships with new workers developed.

It may be important to recognise that, particularly for children in stable, supportive foster placements, social workers and their organisations may not feature as prominently in the grand scheme of things as is assumed by the SWP concept. Holland (2010) found that social workers assumed rather minor roles in looked after young people's narratives about their lives and care relationships. She attributed this to the transitory nature of social work involvement in their lives; the relationships that emerged as most salient for these young people were everyday relationships with carers, birth families and extended family members, friends, partners and pets. If young people enjoy a network of supportive caring relationships, social workers may rightly be peripheral figures in their lives. The social work relationship is likely to be most central and crucial for those young people whose lives are turbulent and for whom positive caring relationships are not readily available. Care leavers are among those most likely to be without such supports but this group also includes children where placements are in jeopardy or where there are long-term problems that make their situation fraught or difficult.

It is important to acknowledge the limits of the findings reported in this paper. As noted, the evaluation is underway at the time of writing and this paper has drawn on interviews 
undertaken early in both the implementation of SWPs and in the evaluation. Many of the professionals interviewed might be said to have a keen interest in the success of the SWPs. As this paper identifies, there are differing models of SWPs emerging and this high level of variation presents challenges for any evaluation or assessment.

\section{Conclusion}

In this round of pilots, SWP providers have included voluntary organisations with established relationships with local authorities, a social enterprise established by staff from the commissioning local authority and one small privately-owned company. There has as yet been no involvement from the large commercial organisations providing fostering services, residential care and home care in the UK. The local context can be seen to impact on local authorities' ability and willingness to engage in this new form of service delivery for statutory children's services. The failure of one of the original pilots to start suggests that where local authorities are preoccupied with major safeguarding or internal restructuring issues, the commitment and energy required for SWP (or indeed any other pilot or demonstrator project) start-up and support may not be available.

The quality of the relationship between SWPs and commissioning local authorities emerges as critical to both effective start-up and their subsequent operation. For future waves of SWPs, trusting relationships between the local authority and the SWP could be fostered at an early stage and the commissioning process could benefit from being redesigned to promote sharing of information and negotiated agreement rather than being conceived as a competitive process designed to produce the best deal for the 
commissioner. Start-up of SWPs could be facilitated by the use of a checklist detailing transfer requirements such as up-to-date case files.

Some controversial aspects of the original SWP model, such as payment by results and the concept of a round-the-clock service for looked after children, have not been consistently retained in the implementation of these first SWPs. Since these elements were the source of some professional resistance to SWPs and concerns about them, continued insistence on their inclusion in the SWP model seems inappropriate.

Where a change of social worker or Personal Adviser is likely, it is particularly important that those children and young people selected for inclusion in an SWP are fully consulted about the change, the reasons are clearly explained to them and that their views are taken into account.Feelings of disempowerment and dissatisfaction might be avoided by ensuring that the proposed move to a SWP is fully discussed with children and young people on an individual basis beforehand and that children's wishes are respected.

This early account of SWPs in their start up-phase highlights the risks of starting up a new venture when children's services are under the political spotlight, when public services are being questioned for their effectiveness and their rationale, and the value of replacing them with private services is yet to be evidenced. The evaluation also provides insights into the benefits of particular models and contexts for delivering SWPs. The picture that emerges is one of a variety of approaches to SWPs and differing degrees of closeness in relationships with commissioning local authority 
children's services; caution is needed in portraying them as monolithic or as completely independent.

\section{References}

Berridge, D. (2011) Reflections on Child Welfare Research and the Policy Process:

Virtual School Heads and the Education of Looked after Children. British Journal of

Social Work. doi: 10.1093/bjs+w/ber038

Brody, S. (2010) We must resist the social work practice model. Community Care,

February 12

Breslow, N.E. (1996) Statistics in Epidemiology: The case control study. Journal of American Statistics Society, 91, pp. 14-28

Cardy, S. (2010) 'Care Matters' and the Privatisation of Looked After Children's

Services in England and Wales: Developing a Critique of independent 'Social Working

Practices. Critical Social Policy, 30, pp. $430-442$.

Coffey, A., and Atkinson, P. (1996) Making Sense of Qualitative Data. London: Sage

Creswell, J. (2009) Research Design: Qualitative, Quantitative and Mixed Methods Approaches. (3rd Edition). London: Sage.Collins-Camargo, C., Ensign, K. and Flaherty, C. (2008). The National Quality Improvement Center on the Privatization of Child Welfare Services: A program description. Research on Social Work Practice, 18, pp. $72-81$.

Department for Education and Skills (2003) Every Child Matters, Green Paper, London: The Stationery Office. 
Department for Education and Skills (2007) Care Matters: Time for Change. Cm 7137. Norwich: The Stationery Office.

Flaherty, C., Collins-Camargo, C. and Lee, E. (2008) Privatization of child welfare services: Lessons learned from experienced states regarding site readiness assessment and planning. Children and Youth Services Review, 30, pp. 809-820. Forrester, D., Goodman, K., Cocker, C., Binnie, C. and Jensch, G. (2009) What is the impact of Public Care on Children's Welfare? A Review of Research Findings from England and Wales and their Policy Implications. Journal of Social Policy, 38, pp. 439456.

Garrett, P.M. (2008) Social Work Practices: Silences and elisions on the plan to 'transform' the lives of children 'looked after' in England. Child and Family Social Work, 13, pp. 311-318.

HM Government (2010) The Coalition: our programme for government. London: TSO. Holland, S. (2010) Looked after Children and the Ethics of Care. British Journal of Social Work, 40, pp.1664-1680.

Hutchfield, J. and Coren, E. (2011) The Child's Voice in Service Evaluation: Ethical and Methodological Issues. Child Abuse Review, 29, pp. 173-186.

Le Grand, J. (2007) Consistent Care Matters: Exploring the potential of Social Work Practices. London: Department for Education and Skills.

Lombard, D. (2010) Should independent GP-style social work practices be rolled out nationally? Community Care, 19 November. Accessed 3 September 2011 http://www.communitycare.co.uk/Articles/2010/11/19/115848/should-independent-gpstyle-social-work-practices-be-rolled-out-nationally.htm 
Mahadevan, J. (2010) Social workers take stance against Midlands pilots? Children \& Young People Now, 18 January.

McCullough, C. and Schmitt, B. (2000) Managed Care and Privatisation: Results of a National Survey. Children and Youth Services Review, 22, pp.117-130.

Secretary of State for Education and Skills (2006) Care Matters: Transforming the Lives of Children and Young People in Care. Cm 6932. Norwich: TSO.

Sellick, C. (2011a) Commissioning Permanent Fostering Placements from External Providers: An Exploration of Current Policy and Practice, British Journal of Social Work, 41, pp. 449-466.

Sellick, C. (2011b) Independent fostering providers: Predators or pioneers, partners or procured? Adoption \& Fostering Journal, 35, 1, pp.33-43.

Stein, M. (2006) Research Review: Young People leaving care. Child and Family Social Work, 11, pp.273-279.

Snell, L. (2000) Child-welfare Reform and the Role of Privatization. Policy Study 271. Los Angeles CA: Reason Public Policy Institute.

Zullo, R. (2006) Is social service contracting coercive, competitive or collaborative? Evidence from the case allocation patterns of child protection services. Administration in Social Work, 3, pp. 25-42. 